\title{
RELACIONES INTERNACIONALES DEL INSTITUTO ESPAÑOL DE MUSICOLOGÍA DURANTE LOS PRIMEROS AÑOS DEL TRABAJO DE MIGUEL QUEROL: EL EJEMPLO DE HEINRICH BESSELER ${ }^{1}$
}

\author{
Rolf BäCKER
}

\section{Resumen}

El presente artículo centra su interés en el musicólogo alemán Heinrich Besseler, y su relación con el Instituto Español de Musicología a través de Miquel Querol y Higini Anglès, relación de algún modo paradigmática para la participación de la musicología española de la época en la red internacional de instituciones y personas dedicadas a la disciplina. Basándose en la documentación guardada en el Departamento de Musicología de la Institució Milà i Fontanals, la presente contribución pretende arrojar alguna luz sobre Besseler y el IEM, cuya colaboración se concretó en un estudio presentado a escala internacional en el IV Congreso de la Sociedad International de Musicología.

\begin{abstract}
The present paper is devoted to the German musicologist Heinrich Besseler and his relation with the Instituto Español de Musicología through Miquel Querol and Higini Anglès, which can be regarded as a paradigm for the participation of Spanish musicology in the international network of institutions and individuals devoted to the discipline. Relying on documentation conserved in the Department of Musicology at the Institució Milà i Fontanals, the present contribution expects to cast some light on Besseler and the IEM, whose collaboration led to a study that was presented on internacional level at the IV Congreso of the Internacional Musicological Society.
\end{abstract}

El 28 de diciembre de 1949, el musicólogo alemán Heinrich Besseler escribió una carta cuya traducción se expone íntegra a continuación ${ }^{2}$ :

\section{Señor secretario!}

Supe a través de su carta del 10 de diciembre que el Instituto Español de Musicología me había nombrado "Colaborador Honorario". Fue una gran sorpresa para mí recibir ese homenaje que no merezco por mi humilde labor. Sin embargo, tengo el deseo de expresar mi satisfacción y mi gratitud especial al respecto.

Desde el trabajo polifacético del maestro Felipe Pedrell, el nombre de la ciudad de Barcelona goza de buena reputación en la musicología. Continuando la obra iniciada por él, era Higinio Anglés quien

1. Agradecemos al Dr. Antonio Ezquerro Esteban, jefe del Departamento de Musicología de la Institución "Milà i Fontanals" (CSIC), Barcelona, su permiso para consultar la documentación y correspondencia conservadas en dicho departamento.

2. Véase Fig. 1 en el Anexo. 
no sólo ofreció al mundo abundantes trabajos importantes, sino que también, a través de la fundación del Instituto Español de Musicología, creó un centro cuya labor es reconocida por los eruditos de todos los países.

Han sido especialmente estrechos desde siempre los enlaces entre España y Alemania en el campo de la musicología. Considero un gran honor el participar personalmente en esta relación amistosa entre los dos países. Será para mí una misión honrosa fomentar estos enlaces con todas mis fuerzas. Le ruego cuente en este sentido siempre con mi disposición a colaborar.

Transmitiéndoles a Ud., Señor Secretario, y a los miembros del Instituto Español de Musicología los mejores deseos para el año nuevo, le saluda muy atentamente

Heinrich Besseler

Como se ve, el musicólogo alemán se refiere aquí a una larga tradición de encuentro e intercambio entre su país natal y España, destacando sobre todo los papeles de Higinio Anglés y del Instituto Español de Musicología. Sin embargo, las relaciones que mantenía el fundador del Instituto y, después de su llamamiento al Pontificio Istituto di Musica Sacra ${ }^{3}$, Miguel Querol, no se reducían, ni mucho menos, a Alemania. Un primer vistazo a la abundante correspondencia que se encuentra conservada en el Departamento de Musicología de la Institución "Milà i Fontanals"4, ya deja entrever una tupida red que unía el Instituto con los principales centros musicológicos europeos e incluso americanos ${ }^{5}$. Dada la abundancia del material a estudiar y el espacio reducido de que dispongo aquí, he escogido para esta ocasión un ejemplo significativo de los primeros años del Instituto Español de Musicología, que ilustra tanto las relaciones personales y científicas entre España, Alemania y otros países, como la creciente conciencia e interés por cuestiones españolas por parte de la musicología extranjera.

Entre los estudiantes que Higinio Anglés conoció en sus estancias en las ciudades alemanas de Friburgo y Gotinga (1923/24 y 1928, respectivamente) ${ }^{6}$, se encontraba también el joven Heinrich Besseler. La primera carta que he podido localizar en la correspondencia conservada en el Departamento de Musicología de la Institución "Milà i Fontanals" y en la cual se menciona su nombre, del 22 de noviembre de 1946, fue mandada por Anglés a Jacques Handschin en Basilea e informa, por un lado, que Marius Schneider -otro célebre musicólogo alemán que había dirigido el Phonogrammarchiv en Berlín y que ocuparía la sección de etnomusicología del IEM hasta que se crease para él una cátedra de etnomusicología en Colonia, debido también a los contactos de Anglés - ya trabajaba en Barcelona desde 1944, y, por otro lado, pregunta de qué manera se podría ayudar a

3. Dicho nombramiento se produjo el 21 de octubre de 1947, cfr. LLORENS CisTERÓ, Josep Maria: “Anglés Pamies, Higinio", en Diccionario de la Música Española e Hispanoamericana. Madrid, Sociedad General de Autores y Editores, 1999, vol. 1, p. 467.

4. El mencionado Departamento continúa la labor iniciada por el Instituto Español de Musicología dentro del marco del Consejo Superior de Investigaciones Científicas, por ello, toda la documentación correspondiente a la historia del I.E.M. se encuentra en su sede.

5. Así, entre los colaboradores honorarios que se nombraron el 1949, junto a Heinrich Besseler, figuraban Adolfo Salazar y Miguel Bernal (México), Paul Smets (Alemania), Gilbert Chase (USA), Henry George Farmer (Gran Bretaña), Isabel Pope (USA), André Schaeffner y Alexis Schottin (Francia), cfr. GonZÁLEZ VALLE, José Vicente: "Pasado y presente del Instituto Español de Musicología (hoy Unidad Estructural de Investigación - Musicología) del Consejo Superior de Investigaciones Científicas (1943-1993)", en Anuario Musical XLVIII (1993), p. 5.

6. Cfr. Llorens Cisteró, Josep Maria, "Anglés Pamies, Higinio", op. cit., p. 467.

7. Cfr. GonzÁlez VAlle, José Vicente: "Dimensión internacional de monseñor Higini Anglés", en "Actes del Congrés Internacional Higini Anglès i la Musicologia Hispànica”, en Recerca Musicològica, IX-X (1989-1990), pp. 260 y ss. 
Besseler, entre otros. En aquella época (poco después del final de la Segunda Guerra Mundial), marcada por inmensas dificultades económicas y administrativas, el musicólogo suizo serviría más de una vez como intermediario para asegurar la correspondencia entre Anglés y Besseler, una correspondencia que no se reducía a cartas sino que incluía paquetes con víveres muy básicos -café, tocino, azúcar, embutidos, etc.- pero de difícil acceso o disponibilidad reducida o nula en la Alemania de la posguerra. Conviene resaltar este hecho, ya que es uno de los temas más destacables en la correspondencia durante la segunda mitad de la década de 1940. En total, son 14 paquetes cuya llegada acusa Besseler, agradeciendo el envío, desde diciembre de 1947 hasta agosto de 1949, cuando pide no mandar más porque ya no hay tanta escasez de víveres, salvo respecto al café 8 .

A finales del año 1948, Besseler se dirigió a Anglés a causa de algunas preguntas respecto a un tema que ocuparía buen espacio en su correspondencia a partir de entonces, y cuya proyección internacional vendría a manifestarse en varios niveles. Refiriéndose al décimo capítulo de su libro "Bourdon und Fauxbourdon" sobre los instrumentos utilizados, le pidió informaciones acerca de la cobla, aunque todavía la llamó "Sardana-Kapelle", en concreto, sobre los instrumentos del conjunto y su historia $^{10}$. En su respuesta ${ }^{11}$, Higinio Anglés le aseguró ocuparse de la cuestión, con el resultado de que un mes después ${ }^{12}$ le mandó la descripción de una sardana y de los instrumentos, añadiendo que le había rogado a Joan Tomàs ${ }^{13}$, entonces sub-director del "Orfeó Català" y colaborador del Instituto Español de Musicología en materias relacionadas con el folklore, le escribiese algo al respecto.

En otra carta, datada el 5 de marzo de $1949^{14}$, Heinrich Besseler acusa haber recibido las explicaciones de Tomàs, pide dos discos de sardanas para poder demostrar el sonido de una cobla en dos

8. Véase Fig. 2 en el Anexo.

9. BESSELER, Heinrich: Bourdon und Fauxbourdon. Studien zum Ursprung der niederländischen Musik. Leipzig, Breitkopf \& Härtel, 1950. El capítulo X lleva el título "Chorklang und Instrumente”, y en las páginas 189 y ss., se refiere al tema mencionado.

10. Carta de Heinrich Besseler a Higinio Anglés del 02.12.1948:

"En el capítulo X [del libro sobre el fauxbourdon] hablo de la práctica de ejecución y de los instrumentos, y allí he hablado, entre otras cosas, de las informaciones sobre música de viento del siglo XV. Ud. conoce la pieza instrumental "Alta" en Madrid 2-1-5 Nr. 321 (según su numeración), cuyo principio imprimí en el libro de la Edad Media [Die Musik des Mittelalters und der Renaissance. Potsdam, Akademische Verlagsgesellschaft Athenaion, 1931-1934], p. 222. Mientras tanto encontré que "Alta" no se refiere a un baile (porque la pieza no es estrictamente para bailar, sino para escuchar). Según Tinctoris se llamaba "alta" a un grupo de chirimías, bombardas y sacabuche, y eso parece que significa "alta musica" = fr. "haute musique", "música alta" (opuesta la música de cámara más baja = "basse musique"). Esta alta parece que era el conjunto de baile de las cortes y de la gente alta. De ella proviene, seguramente, el conjunto de la sardana, ya que la chirimía "tenora" no es sino un desarrollo ulterior de la bombarda-tenor. Me gustaría saber lo siguiente:

1) ¿El instrumento se llama simplemente "tenora”, o de otra manera? Y, ¿está construido exactamente como un oboe mayor, o más simple, con un fuerte sonido de chirimía? Y, ¿cómo se llama el oboe o chirimía soprano normal en el conjunto de la sardana? ¿Tiple?

2) ¿Existe un buen estudio sobre la combinación de instrumentos y la historia del conjunto de sardana? Creo que aquí sobreviven vestigios de la vieja tradición juglaresca, que estaba vinculada, en el siglo XV, con la "alta" - ya que parece que entonces se tocaba la música de baile sin partitura, en la mayoría de los casos sobre la base de un "tenor" que era tocado por la bombarda-tenor y con el que los demás instrumentos improvisaban. ¿Cómo es eso en el caso de la sardana: allí se sigue improvisando, o se aprenden piezas compuestas de memoria? [...].

Véase Fig. 3a y $3 b$ en el Anexo.

11. Carta de Higinio Anglés a Heinrich Besseler del 23.12.1948.

12. Carta de Higinio Anglés a Heinrich Besseler del 22.01.1949.

13. Cfr. Martí I Pérez, Josep, "Tomàs Parés, Joan”, en Diccionario de la Música Española e Hispanoamericana, vol. 10. Madrid, Sociedad General de Autores y Editores, 2002, pp. 338 y ss.

14. Véase Figs. $4 \mathrm{a}$ y $4 \mathrm{~b}$. 
piezas "típicas y famosas"15 y vuelve a plantear una serie de preguntas acerca de la cobla. Aquí surge por primera vez la idea de presentar los resultados de esa investigación en el marco del IV Congreso de la Sociedad Internacional de Musicología, que se iba a celebrar en Basilea en el mismo año. Son dos los aspectos de este hecho que llaman la atención: por un lado, como Besseler dice literalmente, que su idea era "evocar la memoria de Barcelona y agradecer con ello el maravilloso congreso" 16 , organizado por Higinio Anglés el año 1936. Así, se refiere a través de su comunicación a otro congreso que había comprobado la internacionalidad de la musicología española antes de las dos guerras que sufrieron España y Alemania, respectivamente. La profunda impresión que aquel evento le había producido resulta palpable en otra carta suya del 29 de agosto de 1949, cuando consideró una suerte que el congreso hubiese podido realizarse pocas semanas antes de estallar la guerra civil. Por otro lado, se dedicó a un tema -y parece que vale la pena destacarlo, ya que el motivo de la presente contribución es el homenaje a un musicólogo catalán- de los que más estrechamente se suelen relacionar con la identidad cultural catalana: la sardana y la cobla. Que Besseler era perfectamente consciente de este hecho y sus connotaciones lo demuestran varias cartas. En la del 23 de diciembre de 1947, por ejemplo, ya había subrayado el mérito de Anglés por haber dado a conocer la música de España y Cataluña ${ }^{17}$; resulta igualmente significativa su preocupación por escribir los nombres catalanes de manera correcta, como se manifiesta en su carta del 29 de agosto de $1949^{18}$ citada más arriba, donde también informa haber mandado a Friedrich Blume dos artículos sobre la "cobla" y la "alta", para que "ojalá sea pronto que los países extranjeros se fijen más en las cosas buenas que ofrece Cataluña" 19 . Es interesante notar que -a la hora de publicar la comunicación en el Anuario Musical y de pagar los gastos- los responsables quitaron algo de esa ponderación, tal vez a causa de las circunstancias políticas de la década de 1940, una impresión que se impone cuando Anglés, en su carta a Joan Tomàs del 2 de abril de

15. Carta de Heinrich Bessler a Higinio Anglés del 05.03.1949: “[...] - die Stücke sollen möglichst typisch und berühmt sein!”. Lo subrayado es mío y corresponde al pasaje citado arriba.

16. "Es ist meine Idee, beim Kongress in Basel 1949 mit diesem Referat die Erinnerung an Barcelona wachzurufen und damit einen Dank abzustatten für den wunderschönen Kongress, den Sie 1936 organisiert haben!”, ibid. Lo subrayado es mío y corresponde al pasaje citado arriba.

17. Carta de Heinrich Besseler a Higini Anglès del 23.12.1947: "Lo que Ud. ha dado a nuestra disciplina, se puede decir en una frase. Hasta 1924, España-Cataluña era la "terra incognita" de la música europea - hoy, es el país más conocido, o lo será pronto: ¡eso es su mérito! La investigación musical de todo el mundo le desea hoy con cordial simpatía suerte y éxito en todo lo que Ud. aún prepare y planee, y muchos años aún de actividad tan enérgica como le ha sido propia hasta ahora!". Vale la pena destacar que uno de los motivos de esta carta era el 60 cumpleaños de Higinio Anglés, al cual se refiere Besseler en las primeras líneas. Véase Fig. 5a en el Anexo. En esta ocasión, la esposa de Besseler le añadió una carta escrita a mano que reproduzco en la Fig. $5 \mathrm{~b}$ en el Anexo.

18. Carta de Heinrich Besseler a Higinio Anglés del 29.08.1949:

"[...] Tengo dos preguntas más que nadie me sabe aclarar:

1) La ortografía de las palabras catalanas con 'o': jes correcta en todos los pasajes de mi manuscrito? Por favor, compruébelo y anótelo al margen: p. 1 Tomàs - p. 2 Castelló - p. 7 Martí 8 Contrapàs - 9 Toldrà - 9 Català

2) Nombres catalanes: en la página 9 he utilizado las formas españolas (Enrique, Julio, José, Juan, Francisco, etc.) - porque así está [sic!] en las enciclopedias y así se conoce [sic!] en general. ¿Ud. piensa que sería mejor emplear la forma catalana? Y, ¿cómo es para los nombres citados?"”

Véase Fig. 6a y $6 \mathrm{~b}$ en el Anexo.

19. "Auch in Blumes Enzyklopädie erscheint ein Artikel "Alta" und "Cobla", so dass man hoffentlich bald in den fremden Ländern mehr beachtet, was Katalonien Gutes bietet!”, carta de Heinrich Besseler a Higinio Anglés del 29.08.1949. Lo subrayado es mío y corresponde al pasaje citado arriba. 
1949, le rogó se dejase pagar el material requerido por Besseler por Miguel Querol a través del Instituto, "donat que es tracta de coses que es refereixen de ple a la cultura espanyola". Resulta igualmente reveladora la carta del 21 de septiembre de 1949, donde Anglés le pidió a Besseler que no se preocupase respecto a la ortografía correcta de los nombres catalanes, ya que el artículo aparecería en castellano.

Esta traducción del artículo que se había publicado en 1949 en las actas del congreso de Basilea ${ }^{20}$ introduce otro célebre colaborador del Instituto Español de Musicología de aquella época a nivel internacional: Macario Santiago Kastner. Este pianista, clavicembalista y musicólogo inglés residente en Lisboa $^{21}$ mantenía una abundante correspondencia con Higinio Anglés, en la cual -cabe no olvidarlo en la presente ocasión- destaca el "doctorado brillante" de Querol y su gran valor para la musicología española ${ }^{22}$. Después de haber servido ya de intermediario, asegurando así el funcionamiento de la correspondencia entre Besseler y Anglés durante los primeros años de la posguerra, Kastner se ocupó, a partir del septiembre de 1949 y a petición de Anglés, de la difícil tarea de traducir el texto alemán al castellano $^{23}$. Su lectura -que realizó junto a Joan Tomàs- le llevó a pedirle a Besseler algunas rectificaciones, las cuales, consideradas de manera consecuente, pondrían en duda la tesis del autor de una conexión histórica directa entre el conjunto de la "alta" y el de la "cobla". Así, Kastner le advirtió a Besseler, en una carta del 26 de septiembre de 1949, que "los buenos grupos de viento españoles no tenían absolutamente nada que ver con la sardana, que llegó a Barcelona sólo en torno a 1900”24, que "la cobla vieja se componía de cornamusa, tible y timbal" y que "el empleo del trombón es absolutamente moderno" y que fue Pep Ventura quien introdujo la tenora en Barcelona. ${ }^{25}$ Respecto a esta última, añade que "no es por supuesto que la tenora sea el instrumento protagonista y dirija la sardana" y recomienda no generalizar ${ }^{26}$. Acerca del ritmo con su cambio de 6/8 y 3/4 indica que "es propio del "contrapàs" y fue adoptado más tarde por la sardana"27.

Besseler aceptó la crítica de buen grado, como demuestra una carta suya del 16 de octubre de 1949, dirigida a Higinio Anglés, donde agradece las informaciones que le había proporcionado Joan Tomàs; sin embargo, se percibe una actitud un tanto apologética, cuando hace resaltar que nunca ha

20. BESSELER, Heinrich: "Katalanische Cobla und Alta-Tanzkappelle”, en Kongress-Bericht. Internationale Gesellschaft für Musikwissenschaft. Basel 1949. Basilea: Bärenreiter, 1949, pp. 59-69.

21. Alegrria, José Augusto: "A Singularidade da Obra do Prof. Kastner no Panorama Musicológico Português" (Rodrigues, Maria Fernanda Cidrais; Morais, Manuel; Nery, Rui Vieira, eds.), en Livro de homenagem a Macario Santiago Kastner. Lisboa, Fundação Calouste Gulbenkian, Serviço de Música, 1992, p. 19; cfr. también "Macario Santiago Kastner. Curriculum Vitae", ibid., pp. 5-7.

22. Carta de Santiago Kastner a Higinio Anglés del 05.06.1949.

23. Carta de Higinio Anglés a Heinrich Besseler del 21.09.1949.

24. Carta de Macario Santiago Kastner a Heinrich Besseler del 26.09.1949: "Die guten spanischen Bläser haben absolut nichts mit der Sardana zu tun, die ja erst um 1900 nach Barcelona kam, [...]". Véase Fig. 7a y 7b.

25. Ibid.: "Was die Instrumente betrifft, so bestand die Alte [sic!] Cobla aus Cornamusa, Tible und Timbal. Der Gebrauch der Posaune ist absolut neuzeitlich, Pep Ventura gebrauchte sie niemals, Morera auch nicht, überhaupt bestand Venturas Cobla, gemäss Herrn Tomás und anderen Forschern nur aus 10 (zehn) Instrumenten. Die Tenora hat erst Pep Ventura in Barcelona eingeführt." Lo subrayado es mío y corresponde a los pasajes citados arriba.

26. Ibid.: "Es ist nicht selbstverständlich, dass die Tenora das führende Instrument ist und die Sardana leitet. [...] Man kann hier nicht verallgemeinern, [...]."

27. Ibid.: "Der Wechsel im Rhythmus 6/8 und 3/4 ist vor [sic!] allem dem Contrapás [sic!] eigen und wurde von diesem später in die Sardana übernommen". 
sido su intención escribir una historia de la cobla en Cataluña y el Rossellón ${ }^{28}$. Así, se muestra igualmente reservado frente a la idea de ampliar el trabajo para una publicación en España, debido a su condición de extranjero, que sólo le permite plantear algunas cuestiones que luego tendrán que ser estudiadas por especialistas del país, y para la publicación en el Anuario Musical pide un comentario de parte del editor -Higinio Anglés- subrayando que el artículo se dirige a lectores de fuera de España ${ }^{29}$. Tal como se puede comprobar cuando se comparan las dos versiones del texto, las propuestas realizadas por Kastner y Tomàs también entraron en el original alemán ${ }^{30}$, así que se notan muy pocas diferencias en cuanto a la traducción castellana ${ }^{31}$ que, en general, tan sólo intentan suavizar los pasajes donde Besseler se inclina a conclusiones tal vez algo arriesgadas; por ejemplo, cuando se lee en la versión española que "casi no es de dudar de que exista alguna relación entre la práctica de los ministriles del siglo XV y la cobla en su presente compostura"32, mientras que el texto alemán concreta que "apenas caben dudas que haya un camino que lleva de la práctica de los ministriles a la cobla actual"33.

Respecto a las relaciones entre Besseler y el IEM, parece que el nombramiento como "Colaborador Honorario" calmase un poquito la situación algo tensa después de la crítica pronunciada por Kastner y Tomàs frente a ciertos aspectos del trabajo que Besseler había realizado sobre la cobla. Tal como a nivel oficial lo demuestra la carta citada al principio de la presente contribución, Besseler expresa su agradecimiento también en un contexto más íntimo en una carta del 28 de diciembre de 1949 a su amigo Higinio Anglés:

"Mucho me sorprendió que recibiese un documento desde Barcelona con el nombramiento como "Colaborador Honorario" del Instituto Español de Musicología. Nunca esperé tal honor y me da vergüenza porque en realidad no me la merezco. Sin embargo, me alegro mucho: acepto esta amabilidad como una muestra de afecto de parte de Ud., cara amigo, y se lo agradezco mucho. Esté Ud. seguro de que contesto con el mismo afecto y la misma fidelidad. Celebro especialmente que sigan vivas en una forma nueva las viejas buenas relaciones entre Barcelona y Alemania que estableció el maestro Pedrell. Acabo de escribirlo en mi carta de agradecimiento al Sr. Querol, y también se lo quiero asegurar a Ud. Siempre estaré dispuesto a luchar por estas relaciones con España y a intensificarlas a través de un trabajo adecuado" 34 .

28. Carta de Heinrich Besseler a Higinio Anglés del 16.10.1949: "Mir fehlten früher viele Angaben, die nur ein Kenner in Katalonien selbst geben kann. Es wäre gut, wenn sich nun bald ein guter Historiker daran machte, die Geschichte der Cobla in Katalonien und Roussillon zu schreiben. Das kann ich natürlich nicht und habe ich auch nie beabsichtigt!". Véase Fig. 8.

29. Carta de Heinrich Besseler a Higini Anglès del 16.11.1949:

"Un artículo especial para España, de forma más exhaustiva, no lo puedo redactar desde lejos, sin conocimientos más precisos de las cosas. Aquí son los especialistas del país los que tienen que tomar la palabra. Me alegraría que ciertas cuestiones que planteo se estudiasen y que se encontrasen respuestas. Yo como extranjero, no puedo hacer más en este asunto...

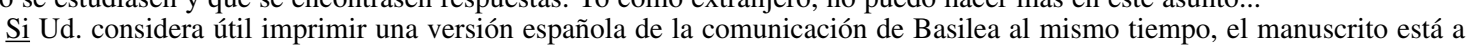
su disposición. [...] En el caso de una publicación en el ANUARIO le rogaría a Ud. como editor, que tal vez añadiese una nota: "Este artículo está dirigido a lectores fuera de España, pero quizá sea útil también en idioma español, para que algunas preguntas que allí se han planteado sean estudiadas por especialistas". Véase Fig. 9a y 9b.

30. BESSELER, Heinrich: "Katalanische Cobla und Alta-Tanzkappelle", op. cit.

31. BESSELER, Heinrich: "La cobla catalana y el conjunto instrumental de danza 'alta'. Comunicación leída en el Congreso Internacional de Musicología de Basilea, en 1949”, en Anuario Musical, IV (1949), pp. 93-103.

32. Ibidem, p. 101.

33. "Katalanische Cobla...", op. cit., p. 67: "Dass von der Spielmannspraxis des 15. Jahrhunderts ein Weg zur Cobla führt, dürfte kaum zweifelhaft sein."

34. Carta de Heinrich Besseler a Higinio Anglés del 28.12.1949. Véase Fig. 10. 
Sea como fuere, vale la pena poner de relieve que las relaciones internacionales del Instituto Español de Musicología, que sin duda deben muchísimo a los contactos personales de su fundador Higinio Anglés y que, después de que él se había trasladado a Roma, quedaron en manos de Miguel Querol, produjeron toda una serie de dedicaciones a fenómenos musicales españoles por parte de investigadores extranjeros. El caso de Heinrich Besseler destaca entre ellos por varias razones: primero, porque colaboran en él, aparte de Besseler y Anglés -su principal persona de contacto y amigo- otros personajes importantes de la época tanto a nivel español como internacional, como Joan Tomàs, Marius Schneider o Macario Santiago Kastner; segundo, porque el resultado fue presentado en un marco cuya envergadura apenas se puede sobreestimar, como era el IV Congreso de la Sociedad Internacional de Musicología; y tercero, porque el tema íntimamente relacionado con la cultura catalana sirvió explícitamente para traer a la memoria el congreso celebrado en 1936 en Barcelona.

\section{Literatura consultada}

AlegríA, José Augusto: “A Singularidade da Obra do Prof. Kastner no Panorama Musicológico Português" (Rodrigues, Maria Fernanda Cidrais; Morais, Manuel; Nery, Rui Vieira eds.), en Livro de homenagem a Macario Santiago Kastner. Lisboa, Fundação Calouste Gulbenkian, Serviço de Música, 1992, pp. 17-32.

BESSELER, Heinrich: "Katalanische Cobla und Alta-Tanzkappelle", en Kongress-Bericht. Internationale Gesellschaft für Musikwissenschaft. Basel 1949. Basilea, Bärenreiter, 1949, pp. 59-69.

-: Bourdon und Fauxbourdon. Studien zum Ursprung der niederländischen Musik. Leipzig, Breitkopf \& Härtel, 1950.

-: 'La cobla catalana y el conjunto instrumental de danza 'alta'. Comunicación leída en el Congreso Internacional de Musicología de Basilea, en 1949”, en Anuario Musical, IV (1949), pp. 93-103.

Bonastre, Francesc: "La institucionalització de la musicologia", en Història de la Música Catalana, Valenciana $i$ Balear. Vol. V: "De la postguerra als nostres dies". Barcelona, Edicions 62, 2002, pp. 139-159.

CABERO, Bernat: "Musicologia hispànica i musicologia internacional. Higini Anglès com a musicòleg i organitzador del III Congrés de la Societat internacional de Musicologia" (Actes del Congrés Internacional "Higini Anglès i la Musicologia Hispànica), en Recerca Musicològica, IX-X (1989-1990), pp. 275-282.

GonZÁLEZ VALLE, José Vicente: "Dimensión internacional de monseñor Higini Anglès" (Actes del Congrés Internacional Higini Anglès i la Musicologia Hispànica), en Recerca Musicològica, IX-X (1989-1990), pp. 249-262.

-: "Pasado y presente del Instituto Español de Musicología (hoy Unidad Estructural de Investigación Musicología) del Consejo Superior de Investigaciones Científicas (1943-1993)”, en Anuario Musical, XLVIII (1993), pp. 3-10.

Llorens Cisteró, José María: “Anglés Pamies, Higinio", en Diccionario de la Música Española e Hispanoamericana, vol. 1. Madrid, Sociedad General de Autores y Editores, 1999, pp. 467-470.

"Macario Santiago Kastner. Curriculum Vitae" (Rodrigues, Maria Fernanda Cidrais; Morais, Manuel; Nery, Rui Vieira, eds.), en Livro de homenagem a Macario Santiago Kastner. Lisboa, Fundação Calouste Gulbenkian, Serviço de Música, 1992, pp. 5-7.

Martí I PÉrez, Josep: “Tomàs Parés, Joan”, en Diccionario de la Música Española e Hispanoamericana, vol. 10. Madrid, Sociedad General de Autores y Editores, 2002, pp. 338 y ss.

RAmió, Concepció: "La sardana, la música de cobla i els esbarts", en Història de la Música Catalana, Valenciana $i$ Balear. Vol. VI: "Música popular i tradicional”. Barcelona, Edicions 62, 2001, pp. 114-159.

SChIPPERGES, Thomas: "Besseler, Heinrich", en Die Musik in Geschichte und Gegenwart. Personenteil, vol. 2. Kassel/Basilea/Londres/Nueva York/Praga, Bärenreiter; Stuttgart/Weimar, Metzler, 1999, pp. 1514-1520. 


\section{ANEXOS}

Prof.H.Besseler

Heidelberg

Kapellenweg 9
Heidelberg, den 28. 12. 1949

An den Sekretär des

Instituto Español de Musicología Senor Miguel $Q$ u e $r \circ 1$ $B$ a $r$ c e lo n a

\section{Herr Sekretär!}

Durch Ihren Brief vom 10. Dezember erfuhr ich, dab das Instituto Español de Musicología mich zum "Colaborador Honorario" ernannt hat. Ich bin gänzlich ïberrascht durch diese Ehrung, die ich durch meine bescheidene Arbeit nicht verdient habe. Umso mehr ist es mir ein Bedïrnis, meiner Freude hieriber und meiner besonderen Dankbarkeit Ausdruck zu geben.

Seit der vielseitigen Tätigkeit des Altmeisters Felipe Pedrell hat der Name der Stadt Barcelona einen guten Klang in der Musikwissenschaft. Als Fortsetzer des von inm Begonnenen hat Higinio Angles nicht nur eine Fiulle bedeutender Arbeiten in die Welt gehen lassen, sondern durch Gründung des Instituto Español de Musi cología ein Zentrum geschaffen, dessen Tätigkeit von der Wissenschaft aller Länder dankbar anerkannt wird.

Besonders eng waren seit jeher die Beziehungen zwischen Spanien und Deutschland auf dem Gebiete der Musikwissenschaft. Ich empinde es als hohe Ehre, mit meiner Person an diesem freundschaftlichen Verhältnis beider Lönder teilzuhaben. Es wirà mir ei ne ehrenvolle Aufgabe sein, die Beziehungen zu Spanien nach besten Kräften zu fördern. Ich bitte Sie, in diesem Sinne stets auf meine Bereitschaft zur Mitarbeit zu zählen.

Indem ich Ihnen, Herr Sekretär, und den Mitgliedern des Instituto Español de Musicologia die besten Wïnsche zum neuen Jahr übermittle, begrüBe ich Sie in ausgezeichneter Hochschätzung

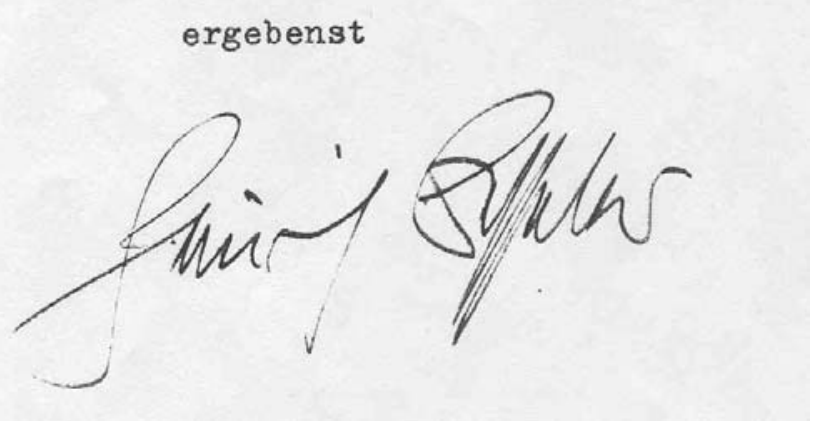

Fig. 1. 


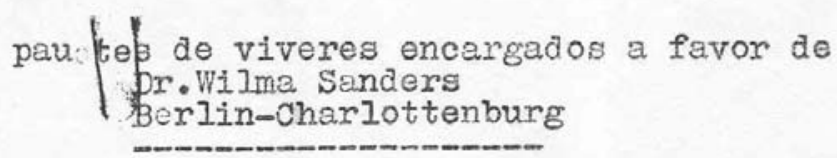

14.1 .1948

$\frac{1}{1}$ Blitzpaket $\underset{\text { Dinemark }}{\text { Suise }}$

5.11 .1947 I Blitzpaket Danemark

18.6.47 I Typ Danemark

18.1.1947 I STandard

segrin su carta del 20.12.47 se ha encargado

en fecha del 14 de enero de 1948 los siguientes

parats paquetes:

I Blitzpaket Danemark

1 idm. Suisse a

Senders - Berlin

I. Blitzpaket Denemark

a Heinrich Besseler-Heidelberg

I Blitzpaket Suisøe

a Otto Usproung

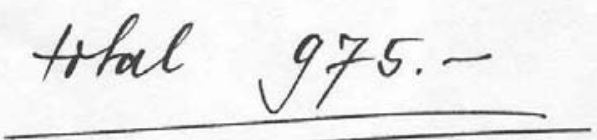

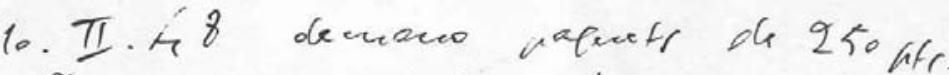

a Frodrid per al Dr. Reneler, Kourfe

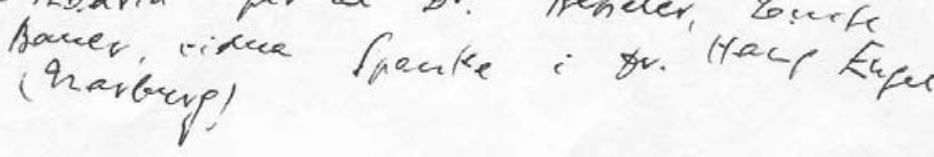

$$
\begin{aligned}
& 3.48
\end{aligned}
$$

Fig. 2. 
Srof. Ir. ST. Zotheter

Mit grober Freude erhielt ich Ihre Zeilen vom 23. November, nachdem ich so lange nichts mehr von Ihnen hörte. Auch ein Paket aus der Schweiz traf inzwischen wieder ein: dafür wieder sehr herzlichen Dank, auch von meiner Frau! Die Lage hat sich in vielem sehr gebessert, aber gerade das wichtigste fehlt uns: Fett und Fleisch, und so sind wir Ihnen fir jedes neue Paket immer noch von Herzen dankbar. Ich wïnschte nur, ich könnte Ihnen irgendeinen Gegendienst leisten - aber nicht einmal etwas Gedrucktes kann ich bisher senden! Kapitel I des Fauxbourdon-Buches ist längst im nächsten Acta-Heft gedruckt, aber bis ich die Separata bekomme, wira wohl noch einige Zeit vergehen. Wegen des Buches habelich eine Frage, für deren Beantwortung ich Ihnen sehr dankbar wäre.

Ich bespreche im X!Kapitel Auffihrungspraxis und Instrumente und habe dort $\mathrm{v}, \mathrm{a}$. die Angaben ibber Blasmusik im 15. Jahrhundert besprochen. Sie kennen den Instrumentalsatz "Alta" in Madrid 2-1-5 Nr.321 (Ihrer Zählung), dessen Anfang ich im Mittelalterbuch S. 222 abdruckte. Inzwischen fand ich, daB "Alta" wohl nicht einen Tanz bezeichnet (denn das Stïck ist kein eigentlicher Tanzsatz, sondern ein Vortragsstiuck). Nach Tinctoris nannte man "alta" ein Bläserensemble aus Schalmeien, Bombarden und Posaune, und das bedeutet wohl "alta musica" = frz." haute musique", "laute Musik" (im Gegensatz zu stillen Kammermusik = "basse musique"). Diese Alta war of fenbar die Tanzkapelle der Höfe und großen leute. Von ihr stamnt sicherlich die Sardana-Kapelle ab, denn die "Tenora"-Schalmei ist nichts als eine Fortbildung dez damaligen Tenor-Bombarda. Ich wïß-

1 dcufenere nun gern folgendes: Und ist es genau wie eine größere Oboe gebaut, loder' einfacher, mit starkem Schalmei-Ton? Und wie nennt man die gewöhnliche DiskantOboe oder-Schlmei in der Sardana-Kapelle, Tiple? 2.) Gibt es eine gute Studie uber die Zusammensetzung und fych Geschichte der Sardana-Kapelle? Ich finde, daB hier ein Uberrest

co screc der "Alta" verknüpft war - denn offenbar hat man damals die Tanzmusik ohne Noten gespielt, meist wohl auf Grund eines "Tenors", der dann von der Tenor-Bombarda gebracht wurde, und zu dem die ubrigen Spieler improvisierten. Wie ist es jetzt bei der Sardana: wird dort auch noch improvisiert, oder lernt man komponierte Stücke auswendig?

Daß Handschin in der Sache de Van so wenig ausgerichtet hat, ist sehr schade: ich wäre gern bereit gewesen, jede halbwegs verninftige Iösung zu ergreifen. Handschin will immer beweisen, daB de Van berechtigt sei, so zu handeln - aber er kann von mir unmöglich erwarten, daßich einfach alles hinnehme, was auf einem Gebiet passiert, auf dem ich manches/gearbeitet habe. Nun ist Dufay I -2 erschienen: in der Anlage ungefxähr so, wie ich vortlo Jahren es gemacht habe. Inzwischen bin ich aber weitergekommen, und es hätte der Wissenschaft sicher genutzt, wenn man diese Resultate sogleich in der Ausgabe selber untergebracht hätte, z. B. die ziemlich genaue Chronologie der Werke, die ich nachweisen kann. Aber nun werde ich das in meinem Buch bringen, hoffentlich bald!

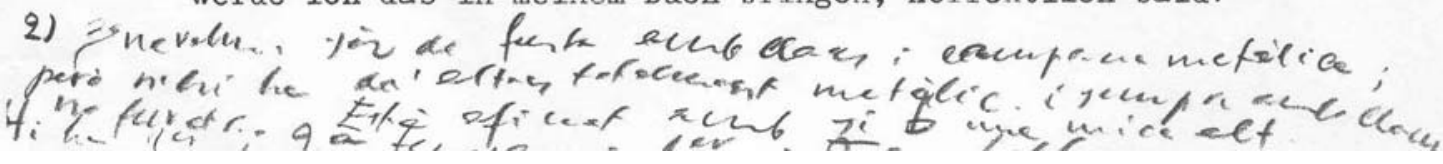

Fig. 3a. 
Über meine Lage will ich Ihnen vertraulich genau Auskunft geben. Nachdem ist durch die Spruchkammer vollständig rehabilitiert war (erst im April erhielt ich das Urteil schriftlich, nachdem es im Januar bereits rechtskräftig geworden war!), konnte ich auf dem Kongre $B$ Rothenburg wieder frei auftreten und reden. Die Folge der persönlichen Kontakte war, daß man mich an zwei Universitäten, darunter Leipzig, für planmäBige Ordinariate vorschlug. In Heidelberg selbst aber gab es Schwierikkeiten, weil gerade zu Ostern der Philosoph Jaspers, meine Hauptstutze in der Universität, von Heidelberg nach Basel fortgegangen war. Das nahm man ihm in Heidelberg sehr tibel ("Fahnenflucht" in die Schweiz, während es den Deutschen so schlecht geht!). Im Laufe des Sommers merkte ich, daß ganz persönliche Gegner gegen mich arbeiteten. Ich erklärte damals dem Rektor der Universität, daB ich gar nicht daran denke, in Heidelberg auf einem Extraordinariat (= Professur 2.Klasse) zu bleiben, da man mir an zwei anderen Universitäten Ordinariate anbieie, und dab ich an Heidelberg nicht mehr interessiert bin. Nun werde ich aber erst 0stern 1949 wechseln, denn jetzt im Winter ist es aus wirtschaftichen Griunden besser, da zu bleiben wo man ist. Leipzig ist eine viel größere und bessere Universität, wo ja fribher Riemann gewirkt hat; vor allem hat man dort noch die große Instrumentensammlung ( rither Heyer-Museum in Köln), jetzt die einzige, die in Deutschland noch ibrig ist! Das bedeutet natürlich sehr viel mehr als das kleine Institut in Heidelberg mit seinen geringen Mitteln und dem bloßen Extraordinariat. Also die nächsten Monate bleibe ich noch hier, aber Ostern gehe ich weg von Heidelberg; bis dahin möchte ich noch die laufenden Arbeiten fertigmachen und wenigstens das Fauxbourdonbuch drucken lassen, wenn es irgend geht.

Nun genug für heute: ich wïrde mich freuen, bald wieder von Ihnen zu hören und bin mit nochmaligem schönstem Dank und herzlichen Grïßen, auch von meiner Frau,

stets Ihr

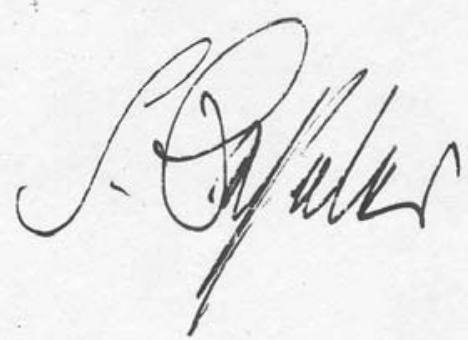

Fig. 3b. 
Iieber, verehrter Freund,

zusammen mit Ihrem Brief vom 22.1. muk ich Ihnen heute eine große Zahl von Sendungen bestätigen, für die ich Ihnen gar nicht herzlich genug danken kann! Zunächst erhielt ich aus Barcelona das Photo der "Alta", dann ein neues Paket aus der Schweiz, das Ende Jamuar hier eintraf, dann die Mitteilung von Herrn Tomas ỉber die "Cobla" beim Begleiten der Sardana: alles höchst wertvoll fïr mich - seien Sie vielmals bedankt! Ich habe wegen der "cobla" noch einige Fragen, die ich auf einem besonderen Blatt notiere, mit der Bitte, dies freundlichst nach Barcelona an Herrn Tomàs oder einen anderen Mitarbeiter zu schicken. Es ist meine Idee, beim KongreB in Basel 1949 mit diesem Referat die Erinnerung an Barcelona wachzurufen und damit einen Dank abzustatten für den wunderschönen KongreB, den Sie 1936 organisiert haben!

Können Sie fïr diesen KongreB (also Ende Juni) vielleicht 2 gute Grammophonplatten mit Sardanas mit bringen, oder durch einen Bekannten mitbringen lassen? Ich nahm 1936 einige sehr schöne Beispiele aus Barcelona mit nach Heidelberg, darunter "La Santa Espina" (die mir sehr gefiel) - aber all diese Platten wurden 1945 von den Amerikanern in der Universität geraubt! So habe ich jetzt gar nichts mehr und bin auf Ihre Hilfe angewiesen. Es handelt sich nur darum, mit 1-2 solcher Platten den "Klang" der Cobla zu zeigen, da die Zuhörer in Basel ihn jaxnicht kennen. Es genügen gewöhnliche Platten aus dem Handel, wie man sie heute kauft - die Sticke sollen möglichst typisch und berïhmt sein!

In den letzten Tagen erhielt ich eine Anzahl wertvoller Bkinde aus Ihrem Institut in Barcelona: 3 von Ihnen selbst, 2 von Marius Schneider, und einen von E.Pujol. Ich danke Ihnen sehr herzlich für dieses großzügige Geschenk! Leider kann ich ihm sehr wenig Gegengaben bieten. Ich habe sofort die von Ihnen gewünschten Biicher hier bestellt, aber bisher ohne Erfolg:

1) K. Strecker, Carmina Cantabrigiensia 1926, erschien bei Weidmann in Berlin; ich habe sowohl in Berlin wie bei der Vertretung dieses Verlages in Frankfurt angefragt, aber bis jetzt kein Exemplar bekommen. Das Buch ist vergriffen; vielleicht ist es möglich, an irgendeiner Stelle noch ein einzelnes Stück zu finden. Sie erhalten es dann sofort. Ein Neudmack ist leider nicht möglich, oder erst in sehr später Zeit, nach vielen Jahren.

2) Hubert Wolking, Guidos Micrologus, ist eine Dissertation aus Minster, $193 \overline{1}$ gedruckt (Jb.Peters 1931, S. 106 enthält den genauen Titel). Diese Dissertationen wuraen in Deutschland nur als sogenannte Pflichtsticke für Universitäten und Bibliotheken gedruckt und sind meist nicht im Handel. Wolking war nicht zu bekommen. Wenn Ihnen an diesem Buch liegt, dann ist der einzige Weg der, ein Exemplar aus der Universitätsbibliothek zu photokopieren oder einen Film zu machen. Das will ich gern tun, wenn Sie es wïnschen. Auch von Streckers Carmina Cantabr.kann natülich ein Film oder eine Photokopie angefertigt werden. Bitte schreiben Sie mir deshalb noch. Wir haben mehrfach verbrannte Werke auf diese Weise ersetzt; es ist natirlich teurer als der gewöhnliche Buchpreis.

Fig. 4a. 
Nach vielen Jahren ist jetzt endlich die erste gedruckte Publikation von mir erschienent seit 1938 habe ich nichts mehr veröffentlicht, zuerst wegen meines Konfliktes mit den Nazis, die mich damals vor ein Gericht stellten und in Berlin aus dem Amt entließen, dann wegen der Schwierigkeiten nach dem Kriege. Wie langsam alles noch immer geht bei uns in Deutschland, sehen Sie daran, dab die Berichte vom Kongre $B$ in Rothenburg (Mai 1948) erst jetzt in Heft 2 unserer Zeitschrift "Musikforschung" erscheinen. Daraus übersende ich Ihnen anbei den Sonderdruck. Nun hoffe ich, daß das Eis gebrochen ist und die Dinge allmählich besser werden.

Kïrzlich schrieb mir der Bärenreiter-Verlag, daß er jetzt die ausländischen Mitglieder selbst beliefern kann (aus seiner Filiale in Basel). So habe ich dem Verlag Ihre Adresse gegeben, weil es auf diese Weise einfacher geht. Vom Jahrgang 1,1948 der "Wusikforschung ist kürzlich Heft $2 / 3$ erschienen; dann folgt noch Heft 4 im April. Dieser Jahrgang ist von mir bereits 1948 bezahlt. Vom Jahrgang 1949 an können Sie, wenn es Ihnen recht ist, von draußen den Mitgliedsbeitrag unmittelbar an Bärenreiter-Basel begleichen. Ich hoffe, daß Sie Heft $2 / 3$ und meinen Sonderdruck bereits erhalten haben. Bald erscheint mehr von mir, wenn es auch niemals so viel sein wird, wie Sie in Ihrem gewaltigen FleiB am Institut von Barcelona geschaffen haben! Dafir meine Bewunderung - die Musikwissenschaft Spaniens verdankt ihre hohe Stellung nur Ihnen allein, uni darauf dürfen auch Ihre Freunde etwas stolz sein! Nun zu meiner Stellung. Ich habe inzwischen gefunden, daß Leipzig unter den heutigen Umständen zu gefährlich ist, und man dort ein Risiko ibernimmt. Schade um die schöne Instrumentensammlung (das fribhere Heyer-Museum in Köln)! Aber ich habe mich doch entschlossen, nicht nach Leipzig zu gehen, sondern den Ruf nach Jen: anzunehmen. Dort ist enfells ein planmäßiges Ordinariat fïr Musikwissenschaft und ein Institut, die Stadt ist unzerstört und als Wohnort recht geeignet. Zunächst behalte ich aber den Wohrsitz in Heidelberg, wo meine Frau zurückbleibt. Ich fahre Ostern nach Jena, hoffe aber, zum Kongreß nach Basel zu kommen.

Meine Frau sagt Ihnen auch diesmal wieder herzlichen Dank für das Paket vom Januar. Die Zustände haben sich in den letzten Wochen soweit gebessert, daß man für den Sommer 1949 wohl wieder auf normale Versorgung rechnen darf. Was aber immer noch fehlt, ist gerade Fett und Fleisch, und so sind wir Ihnen für das letzte Paket herzlich dankbar. Bald wird es nicht mehr nötig sein, die deutschen Freunde zu unterstitzen - daB Sie es so lange und so aufopfernd getan haben, werden wir nie vergessen! Es grïßt Sie herzlich, mit schönen Empfehlungen von meiner Frau,

Ihr

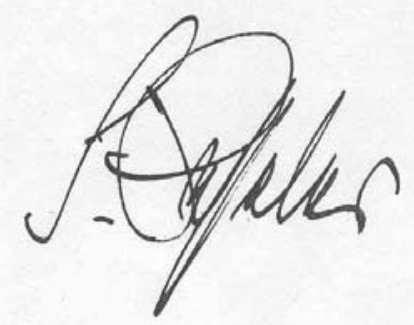

Fig. $4 b$. 
Prof.H.Besseler Heidelberg Kapellenweg 9

\author{
Heidelberg, den 23.12.1947
}

Rev.

Prof. Higini Angless / Rome

Piazza S.Agostino 20

Lieber, verehrter Freund!

Wenn ich meinem Briefe vom 18. Dezember sogleich noch diese Zeilen folgen lesse, so geschieht es wegen des festlichen Tages, den wir - Ihre persönlichen Freunde - und daruber hinaus die ganze Musikwissenschaft in allen Iändern mit Freude begeht:

Ihr 60.Geburtstag ist ein wirklicher Fest- und Gedenktag für uns alle! Ich erinnere mich so lebhaft, als wäre es gestern, unseres ersten Zusammentreffens in Göttingen und der gemeinsamen Studienzeit beim unvergeßlichen Me1ster Irudwig. Was ist se1t 1924 alles geschehen! Ein Höhepunkt war es für Sie, aber ebenso auch fïr uns Gäste, als Sie 1936 die Musikforscher aus der ganzen Welt in Ihrer schönen Heimatstadt zu einem KongreB versammelten, den kein Teilnehmer jemals vergessen wird. Wie freute ich mich, bei dieser Gelegenheit auch Claris 7 und in Tarragona die Stëtten zu sehen, in denen Sie als "puer altaris" angefangen haben! Und dann kam der Bürgerkrieg, der auch von Ihren Angehörigen schmerzllche opfer forderte und Ihnen fiir drei Jahre die Heimat raubte (auch wenn wir dadurch die Freude hatten, Sie bei uns in Deltschland zu sehen). Dann die Rïckkehr in das Land, in dem sich so vieles geändert hatte - gewiB nicht immer zu Ihrer Befriedigung. Aber die Politik ist leider ein unerfreuliches Kapitel für den Wissenschaftler. Das wissen wir auch hier allzu gut. Trotzdem neuer Aufstieg fïr Sie: das Institut unter Ihrer Ieitung, die ehrenvolle Aufnahme in die Akademie zu Madrid, und zuletzt als Höhepunkt die Berufung nach Rom - das ist allerdings eine Laufbahn, lieber und verehrter Freund, auf die Sie mit Befriedigung zurückbilcken dürfen, ebenso wie wir Innen heute mit freudigem Stolz unsere Glückwinsche darbringen: dern Freund und Meister Higini Anglès!

Was Sie unserer Wissenschaft gegeben haben, das kann man mit einem Satz sagen. Bis 1924 war Spanien-Katalonien die "terra incosnita" der europäischen Musik - heute ist es das am besten bekannte Land, oder wird es bald sein: das ist Ihr Verdienst! Fuir all das, was Sie noch vorbereiten und planen, winscht Ihnen heute die Musikforschung der ganzen Welt mit herzlicher Anteilnahme und Zustimmung: Glìck, Erfolg. und noch viele Jahre ebenso tatkräftigen Wirkens, wie es Ihnen bisher beschieden war!

Was ich an diesem Taze bedaure, ist nur die Tatsache, daß dieser Glückwunsch persönlich bleiben muß. Es wäre meine Absicht gewesen, vor aller offentlichkeit unsere Verbundenheit zu bezeugen und Ihnen gleichzeitig den Dank der deutschen Musikforschung auszusprechen, die Ihnen so ens verbunden und zu solchem Dank verpflichtet ist. Daran war die bisherige Trennung zwischen unseren Ländern schuld - ich hoffe, daß es doch noch in irgendeiner Form möglich ist, diese Ehrung in aller öffentlichkeit nachzuholen. Empfangen Sie also zu Ihrem Ehrentage nochmals alle guten Wïnsche und die herzlichsten Gribe

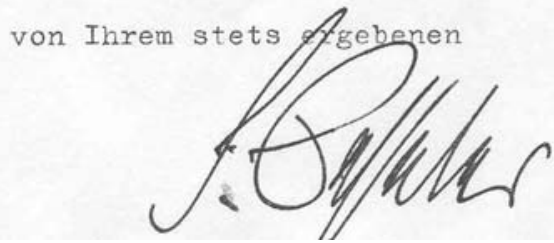

Fig. 5a. 
RELACIONES INTERNACIONALES DEL INSTITUTO ESPAÑOL DE MUSiCOLOGía DURANTE LOS PRIMEROS AÑOS...

287

Sela gechten torr Professor!

Wuch ich möeble Thuen rum os. Jebrortage die allarbighichstew Gu-dorrunsobe sendeu fü gute for sundheid, betriedigande Tätigheit

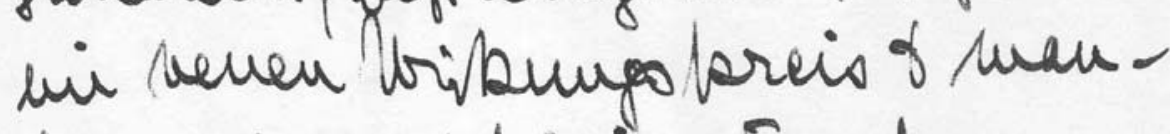
chelai prate tolerive sirenden.

Jur Hore mebrfache ribreude tis, sorpe for uns wiodute anchioh thweu vochuras benglich daubeu.

bas dicie tiefe ni enier Teit bedeuAet wo twen manchenal miald weh

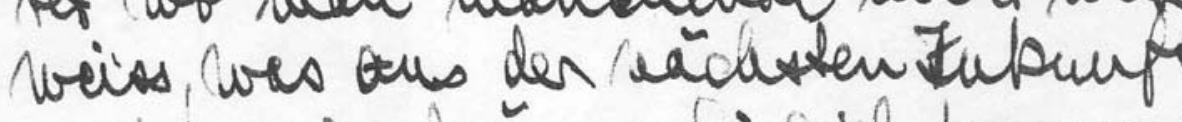
copteir sole bönew fie sieh baum vongteilew.

the berplich engeboue tildegand Besselen

Fig. 5 b.

ANUARIO MUSICAL, N. ${ }^{\circ}$ 61, enero-diciembre 2006, 273-296. ISSN: 0211-3538 


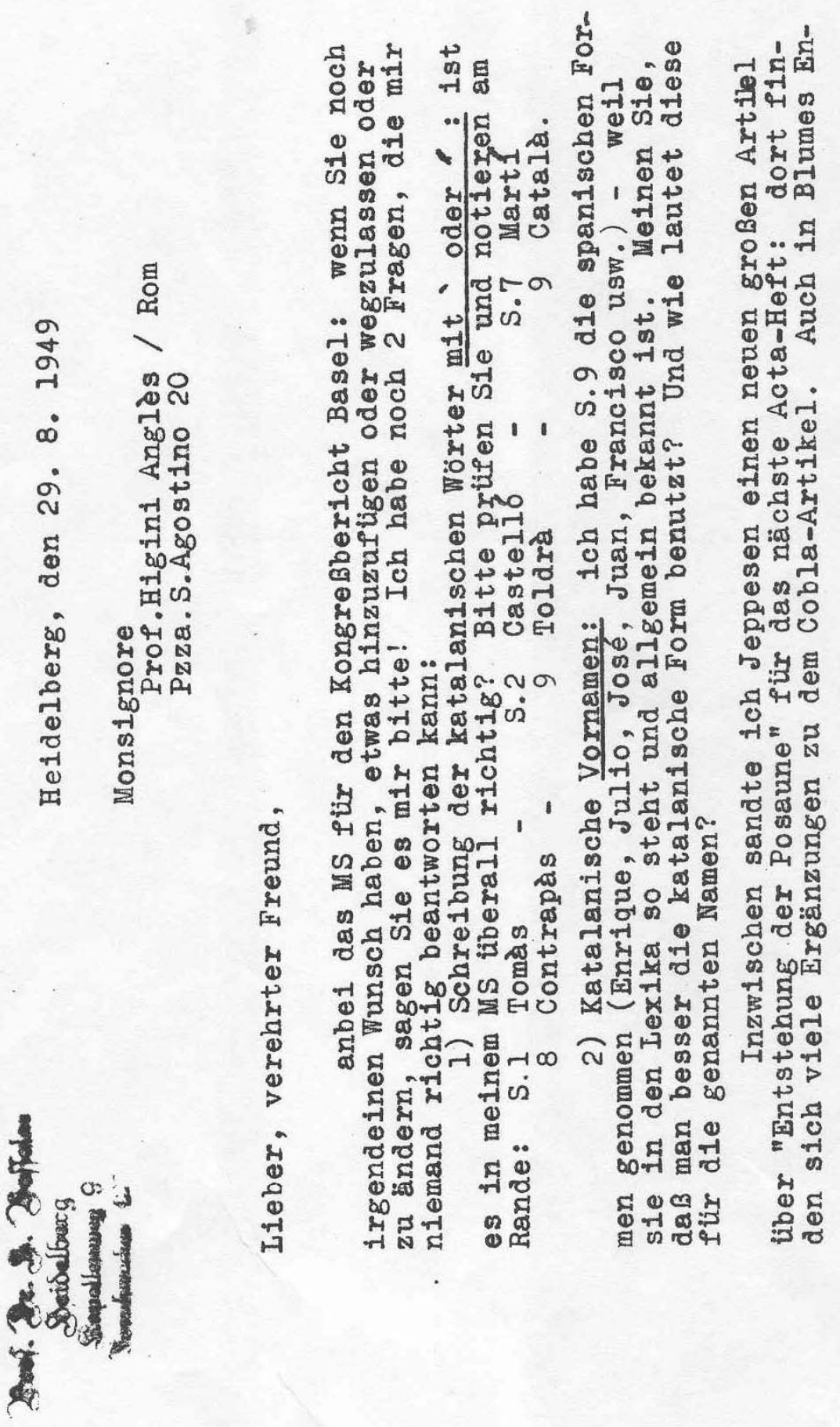




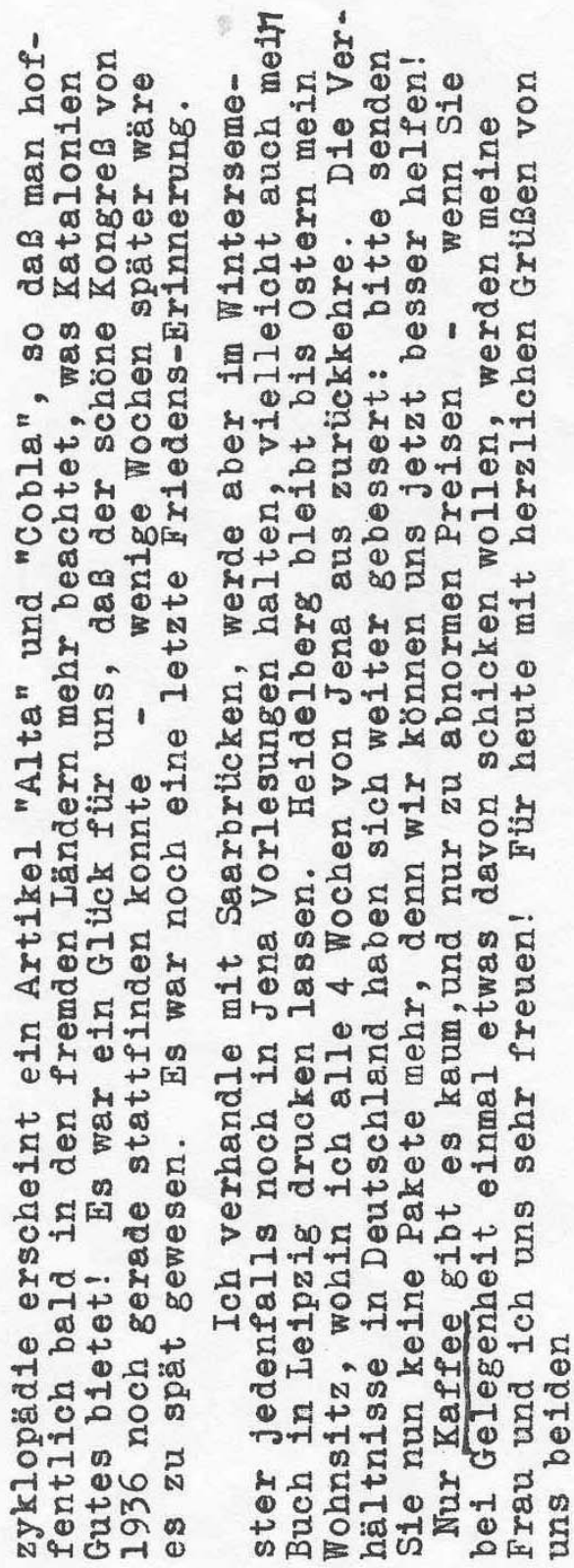




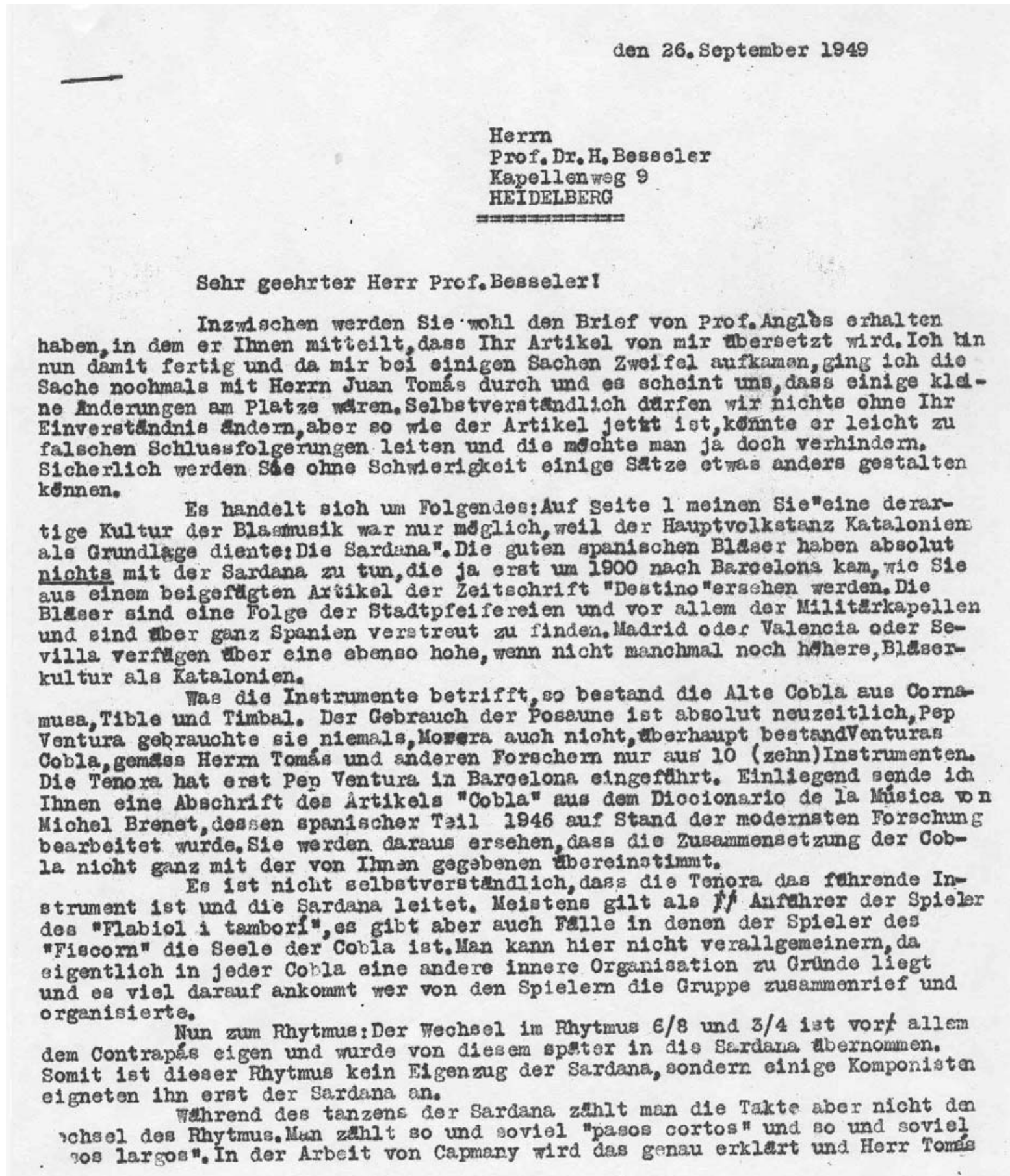

Fig. 7a. 
meint Ihnen diese geeandt zu habun. Es ware verfohlt da von "Ethos der Sohwierlgkeit" gu redon, denn es besteht wirklich keine Sohwlerigkeit und. d1e Sardana le rnen sehx leicht 1 rgend. Neuaniemmilnge aus een anderen spam nisohen provinzen urd sie exhel soht keine tiefe musikalische voxbildung, jedes Dienstmachen flncet slch da sohnell hinein.

Betreffe dex Haute ot basce mas1 gue", Alta und Baja, ,o beschrelbt der Roman "Tirant 10 Blanch" aus dem Jahx 1490 recht gut welche Instiumente der Alta und Felche der Baja angehdrten und wo und wann dle Alta und wo und wann die Baja, spielte, Dsese ganze Frage behandelt' racht auserhrilch der 2. Band Selte $153^{-163}$ des Werkes von Adelfo Salazax: "La Mís1oa on la Sac1edad Europes vom Coleglo de Mexico verlegt und herauggegeben (1944). Das stimmt m1t Ihnen tborein, dooh funrt Balazar mehrexe typlsohe Beweise fllr Span1on an.

Dieses Fitren elnige Anmerkungen fru einlge kleine Rektifikationfen, Angles melnte es were besser Ihnen diese mitzutelien, damit otwal ge Fehler vermieden werden kennen. Bitte nehnen sie die kleinen finderungen selbst vor, nlemand anders hat jo. Befugnia zu so etwas, Ich werde dann nachhor Ihren Text abersetzen.

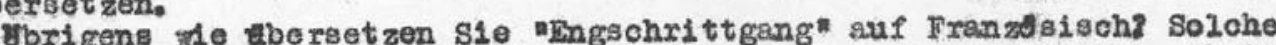
Worte sind in 1ateinischsn Sprachen nioht lolcht zu formen, b1 a jetzt schrieb $1 \mathrm{ch}$ in Klanmern "Pasos cortos" und 11 ess das Doutsche in Anflhrungsatrichen stehen, Ioh fand noch kein rlohtiges glelohwertiges span1sches wort.

B1tte entschuldigen S10 diesen Wrguas, abex es 1st besser in allen Fragen Klarheit zu schaffen. Wis $1 \mathrm{ch}$ aus einem Ihrer Bxiefe orsehe hapert es bel Innen noch mit dem Kaffee. Sowle $10 \mathrm{ch}$ weder in Portugal $\mathrm{k} 1 \mathrm{n}$, sende 1 ch Ihnen von L1ssabon aus eln Paket mit Kaffeebohnen. Da, w1r gerade be1 Portugal sind, so darf $10 \mathrm{~h}$ vielleicht nooh exwlhnen, dasa auch in der portuglea1schen Volkemusik der Feohsel von $6 / 8$ und $3 / 4$ khytmus ru finden 1 st. Das 18t tberhaupt eine beliebto Rhytmik der Ponlnava, nloht umsonst ging $\varepsilon 10$ auch in die Klaviersonston D. Sourlatti' eln, der ja viel aus der Volksmusk schopfte.

In der Hoffnung recht bald wleder von Ihnon su heren, verbleibe $1 \mathrm{ch}$ fur heute mit freundilchen Grassen

Inx erge

Fig. 7b. 


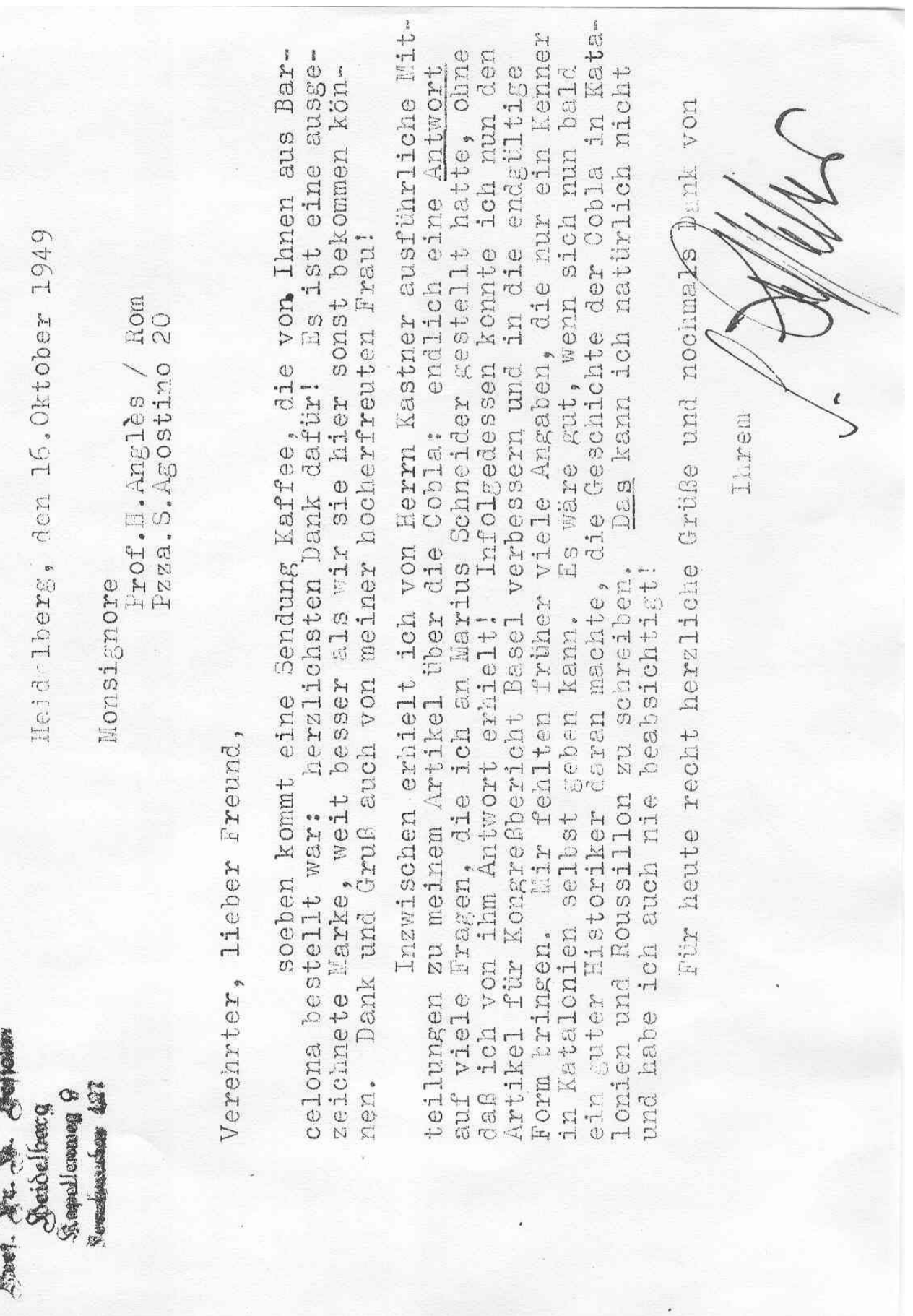




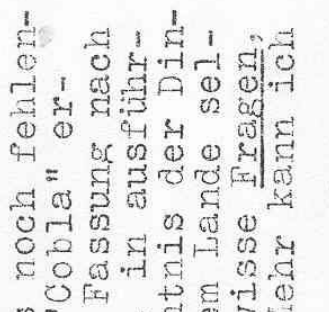

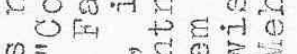

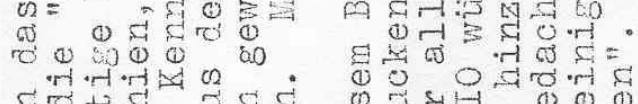

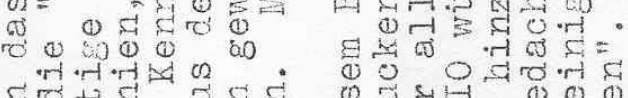
द्ठ

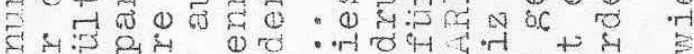

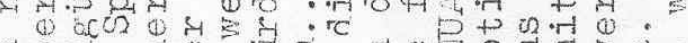

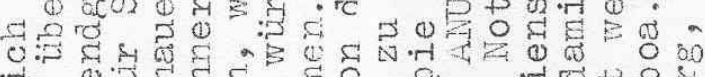

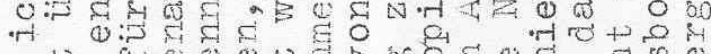

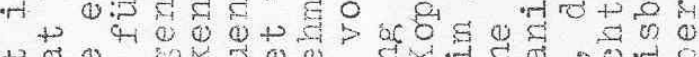

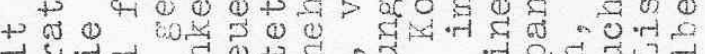

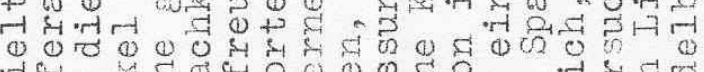

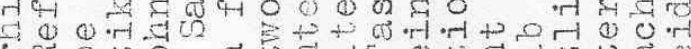

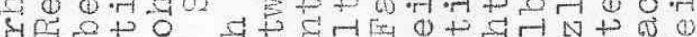
(1) 1 की 00 है

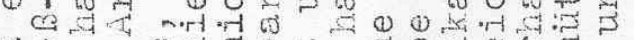
बै सिण क्ष त्रम

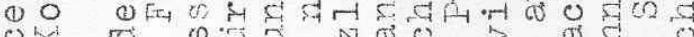
$y$.

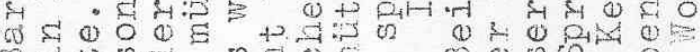

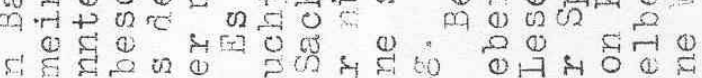

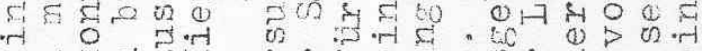

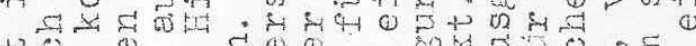

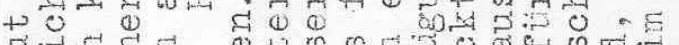

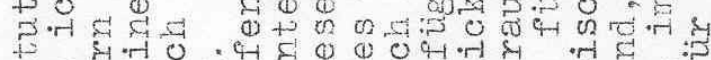

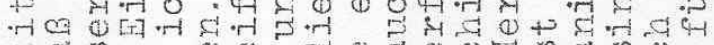

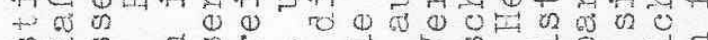

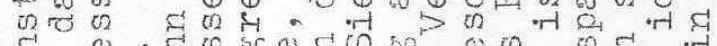

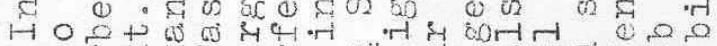

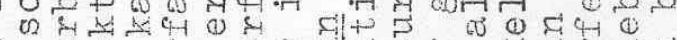

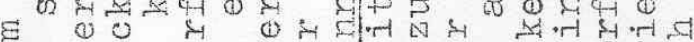

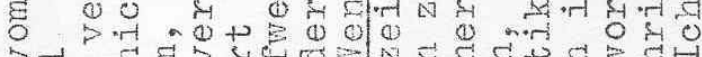

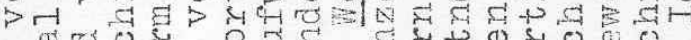

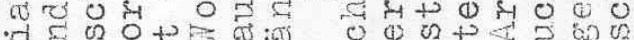

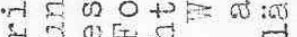

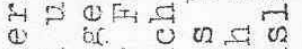

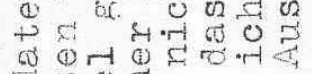
는 $\mathbb{S}$

(1) 1020 क्ष 00

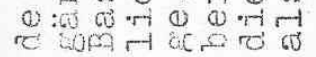

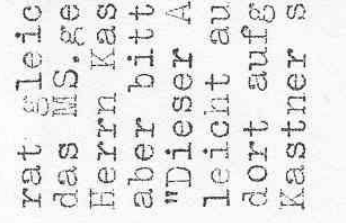


क 0 की

ए 1 s 0 is

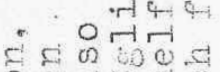

है 0 , 000

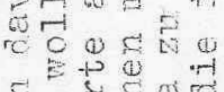

tr

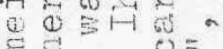

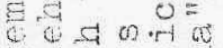

$60 .-1000$ क

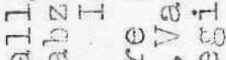

का का प्र 0

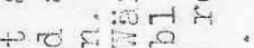

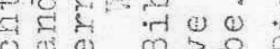

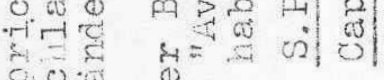

प्रि $0: 6$

o 05

(4) 05

$4+\frac{G}{0}$

is 0

Q 2015

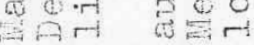

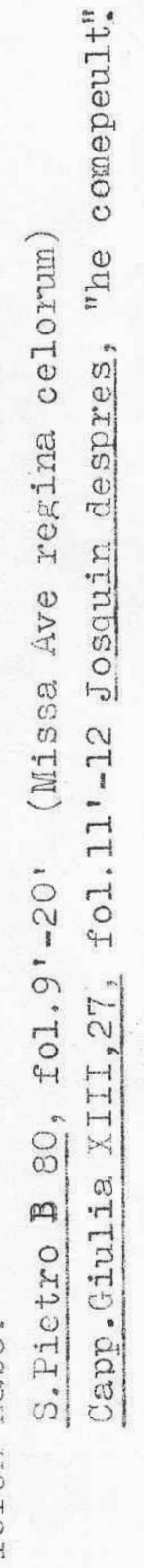

旁

है.

है- का

섬 तो

0.8
0.0
0.40

द 0 का

O क:

द्विध्द

तथ

$\triangle \pm \in 0^{\circ}$

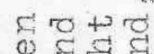

iी

(c) + तै

का कर

0 \& 40

त. तो 0

(t) 0 U

(1) क ए

in 01

व० ?

대뵤

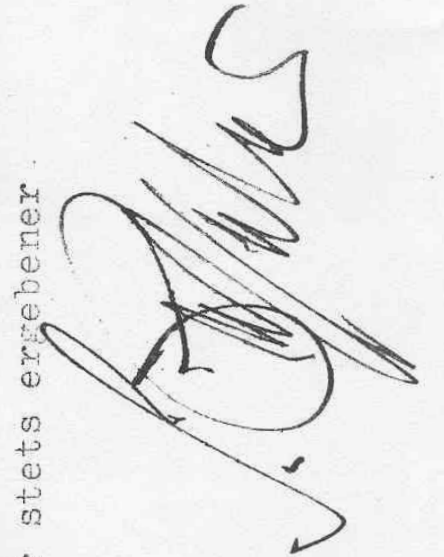

我

द 0 \%

$0 \cdot r-15$

$\mathrm{H}, \mathrm{O}, \mathrm{O}$

0
$0-1$

$=40$

क्ष 10

$\because+\infty$

की $=1$

$\rightarrow 00$

है क्ष

द्व

मि

क

का क्षै:

$400 \mathrm{NO}$

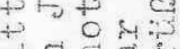

त. 
Prof.H.Besseler Heidelberg

Kapellenweg 9
Heidelberg, den 28. 12. 1949

Monsignore

Prof.Higini Anglès / Rom

Pzza. San Agostino

Lieber, verehrter Freund,

Dank firr Ihren Brief vom 22.Dezember, aus dem ich sehe, welche große Reise Sie hinter sich haben. Gewiß haben Sie dort den Eindruck gewonnen, daß uns Amerika weit voraus ist, was technische und materielle Mittel betrifft?! Wenn ich eine Zeitschrift wie "Notes" ansehe, scheint es fast hoffnungslos, diesen Vorsprung einzuholen. Und trotzdem - die wirklich selbständige Leistung ist bisher äuBerst gering. Vorläufig können winden Wettbewerb ertragen, aber Europa muß endlich zusammenhalten!

$\mathrm{Zu}$ meiner großen Überraschung erhielt ich aus Barcelona ein Schriftstiick mit der Ernennung zum "Colaborador Honorario" des Instituto Espanol de Musicologia. Eine solche Ehre hatte lch nie erwartet und bin in Verlegenheit, da ich sie wirklich nicht verdient habe. Aber trotzdem ist meine Freude groß: ich nehme diese Freundlichkeit als ein von Ihnen, lieber Freund, kommendes Zeichen unveränderter Verbundenheit und danke Ihnen herzlich dafïr! Seien Sie gewiß, daB ich mit gleicher Verbundenheit und Treue antworte. Ich bin besonders erfreut dariber, daB die alten guten Beziehungen zwischen Barcelona und Deutschland, die durch Altmeister Pedrell begrïndet wurden, jetzt in neuer Form weiterleben. Ich habe dies soeben in meinem Dankbrief an Herm Querol geschrieben und möchte es auch Ihnen versichern. Ich werde stets bereit sein, fïr diese Beziehungen zu Spanien einzutreten und sie durch geeignete Arbeit zu vertiefen!

Dank auch für die Bestellung der Photos, die ich im letzten Brief erwähnt hatte. Wegen des Anuario warte ich in Ruhe ab, was geschieht - der deutsche KongreBbericht Basel ist noch gar nicht begonnen worden. Ich bin nun an einigen Artikeln fïr Blumes neue Enzyklopädie (Ars antiqua, Ars nova usw); vielleicht gelingt es mir, in Jena mehr Freiheit zu gewinnen, da ich sobald wie möglich mit der Dufay-Ausgabe fïr Carapetyan beginnen will. Ich habe nicht die Absicht, in Jena zu bleiben, wenn sich die Verhältnisse nicht endgülig kiären. Das wird man aber bald erkennen, sicher im kommenden Jahre 1950.

Nun wïnsche ich Ihnen für 1950 von Herzen alles Gute, zugleich im Auftrag meiner Frau, die Ihnen herzlich für Ihre lieben Grïße dankt und nochmals an all die Hilfe zurïckdenkt, die Sie uns in der schweren Zeit erwiesen haben! Jetzt ist dies tiberstanden, so daB wir nun wohl wieder auf ein normales leben rechnen können. Sobald ich nach Semesterschluß aufatmen kann, will ich mich den Veröffentlichungen Ihres Instituts zu wenden, besonders auch den Cantigas, auf die ich höchst gespannt bin.

Viele herzliche Grüße von Ihrem

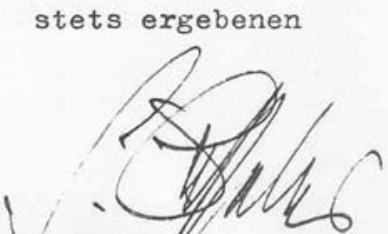

Fig. 10. 